\title{
Erratum to: Fatigue Life Assessment for a Composite Box Girder Bridge
}

\author{
Jun Yong Park ${ }^{1}$ and Ho-Kyung Kim* \\ ${ }^{1}$ Graduate student, Department of Civil and Environmental Engineering, Seoul National University, \\ 1 Gwanak-ro, Gwanak-gu, Seoul, 151-744, Korea \\ ${ }^{2}$ Professor, Department of Civil and Environmental Engineering, Seoul National University, \\ 1 Gwanak-ro, Gwanak-gu, Seoul, 151-744, Korea
}

\section{Erratum to: International Journal of Steel Structures \\ December 2014, Vol 14, No 4, 843-853 \\ DOI 10.1007/s13296-014-1215-x}

In the Acknowledgements page (p. 853), a financial grant has been left out, so it should be disclosed.

Corrected as follows.

\section{Acknowledgments}

This research was supported by grants (KERI-2013-67-534.9607) from the Korea Expressway Corporation. The authors are particularly thankful to Dr. Ahn, Sang Sup for his coordinating the overall field tests and cooperative assistance as a project manager.

The online version of the original article can be found under doi: 10.1007/s13296-014-1215-x.

Published online March 31, 2015

(C) KSSC and Springer 2015

\footnotetext{
*Corresponding author

Tel: +82-2-880-7365; Fax: +82-2-873-2684

E-mail: hokyungk@snu.ac.kr
} 